\title{
Potential of Different Coleus blumei Tissues for Rosmarinic Acid Production
}

\author{
Nataša Bauer ${ }^{1 \S *}$, Rosemary Vukovićç, Saša Likić3 and Sibila Jelaska ${ }^{1}$ \\ ${ }^{1}$ Department of Molecular Biology, Faculty of Science, University of Zagreb, Horvatovac 102a, \\ HR-10000 Zagreb, Croatia \\ ${ }^{2}$ Department of Biology, University of Osijek, Cara Hadrijana 8/A, HR-31000 Osijek, Croatia \\ ${ }^{3}$ Department of Botany, Faculty of Science, University of Zagreb, Marulićev trg 9a, \\ HR-10000 Zagreb, Croatia \\ Received: March 31, 2014 \\ Accepted: January 14, 2015
}

\begin{abstract}
Summary
Rosmarinic acid is one of the main active components of Coleus blumei and is known to have numerous health benefits. The pharmacological significance of rosmarinic acid and its production through in vitro culture has been the subject of numerous studies. Here, the ability of different tissues to accumulate rosmarinic acid and sustainability in production over long cultivation have been tested. Calli, tumours, normal roots and hairy roots were established routinely by application of plant growth regulators or by transformation with agrobacteria. The differences among the established tumour lines were highly heterogeneous. Hairy root lines showed the highest mean growth rate and consistency in rosmarinic acid production. Although some tumour lines produced more rosmarinic acid than the hairy root lines, over a long cultivation period their productivity was unstable and decreased. Further, the effects of plant growth regulators on growth and rosmarinic acid accumulation were tested. 2,4-Dichlorophenoxyacetic acid significantly reduced tumour growth and rosmarinic acid production. 1-Naphthaleneacetic acid strongly stimulated hairy root growth whilst abscisic acid strongly enhanced rosmarinic acid production. Hairy roots cultured in an airlift bioreactor exhibited the highest potential for mass production of rosmarinic acid.
\end{abstract}

Key words: abscisic acid, bioreactor, callus, Coleus blumei, 2,4-dichlorophenoxyacetic acid, hairy root, 1-naphthaleneacetic acid, rosmarinic acid, root, tumour

\section{Introduction}

Plants are an important source of secondary metabolites which can be used as drugs, flavours, fragrances and pesticides. Plant breeding and yield of desired compounds are affected by different parameters such as genetic background, geography and climatic conditions. The use of plant tissue culture for the production of secondary metabolites is an alternative to the collection of wild plants or plant cultivation. In addition, the produc- tion of secondary metabolites often depends on cellular differentiation and many secondary metabolites are preferably synthesized only in specific types of cells or tissues. The manipulation of growth and differentiation by culture medium composition, selection of high-producing cell lines and genetic modification give plant tissue culture great potential for useful and valuable metabolite production. Nowadays, plant cell suspensions and plant organ cultures are used for production of different plant metabolites (1) and large-scale cultivation in bioreactors, 
which is already in use for industrial production of plant metabolites, is under extensive investigation (2).

Coleus blumei is a perennial herb with brightly coloured and patterned leaves, often used as an ornamental plant. This plant is also significant as a medicinal plant used in traditional medicine in Mexico and Malaysia to treat gastrointestinal problems and high blood pressure $(3,4)$. Medicinal properties of Coleus could be due to large quantities of phenolic compounds it contains (5). Phenolic compounds are a very diverse group of biologically active substances whose antioxidant properties reduce the risk of cancer, cardiovascular and chronic diseases (6). The great pharmacological significance of phenolic compounds has led to numerous studies of their synthesis by in vitro grown tissues. The main phenolic compound in $C$. blumei is rosmarinic acid (RA). RA is a polyphenol (ester of caffeic acid and 3,4-dihydroxyphenyllactic acid) with antioxidant, anti-inflammatory, antiviral activities $(7,8)$ and many other health benefits. It can reduce the production of reactive oxygen species, lipid peroxidation and intracellular glutathione depletion (9). It is widely used as a beneficial supplement in cosmetic and pharmaceutical products and is under consideration for different treatments in medicine $(8,10)$.

The biosynthetic pathway of RA is well characterized (11). In contrast to the majority of other secondary metabolites, RA is actively synthesized during tissue growth $(12,13)$. There have been no adverse or toxic effects described for RA, which is very likely the reason why plant cells are able to accumulate high levels of RA (14). In plants, RA is an important antistress compound that accumulates in vacuoles (15), which can be released into the surrounding tissue upon microbial attack and protect the plant against pathogens (16).

Different plant tissues have been studied for their potential to synthesize RA (17). Due to the ability of plant cells to accumulate significant amounts of RA, there is a great interest in optimizing its production processes. Here, we compared the growth rate and RA accumulation of clonally propagated C. blumei plantlets, calli, tumours, normal and hairy roots during long cultivation periods. In addition, we estimated the impact of the plant growth regulators 2,4-dichlorophenoxyacetic acid (2,4-D), 1-naphthaleneacetic acid (NAA) and abscisic acid (ABA) on tissue growth and RA productivity. Finally, we tested whether hairy roots are suitable for cultivation in airlift bioreactors and their potential for mass production of RA.

\section{Materials and Methods}

\section{Plant material and cultivation conditions}

Formerly established sterile plantlets of three different C. blumei genotypes (18) were cultured in 0.3-litre Erlenmeyer flasks containing $50 \mathrm{~mL}$ of Murashige and Skoog (MS) basal medium (19) and subcultured through nodal segments every three months (Fig. 1a). Each tissue type (callus, tumours, normal and hairy roots) was induced on all three C. blumei genotypes. Callus was regenerated on young leaf explants cultured on solid MS medium supplemented with $1 \mathrm{mg} / \mathrm{L}$ of $2,4-\mathrm{D}$ and $0.1 \mathrm{mg} / \mathrm{L}$ of kinetin $(18,20)$. Normal roots were regenerated on young leaf explants cultured on MS medium supplemented with $1 \mathrm{mg} / \mathrm{L}$ of NAA. Tumour induction was performed on young leaf explants cultured in hormone-free MS medium following transformation with Agrobacterium tumefaciens A281 and B6S3 strains while hairy roots were induced with Agrobacterium rhizogenes A4 strain $(21,22)$. Tumours and hairy roots were maintained on hormone-free MS medium.

In line with the experiment, media were solidified with $0.8 \%$ agar and supplemented (before autoclaving) with plant growth regulators (final concentrations of 0.1 , $0.3,0.5,1.0,3.0$ and $5.0 \mathrm{mg} / \mathrm{L}$ of $2,4-\mathrm{D}$, or $1.0 \mathrm{mg} / \mathrm{L}$ of NAA or ABA). Different cultivation methods were examined: (i) static cultivation in plastic Petri dishes, $9 \mathrm{~cm}$ in diameter, each containing $20 \mathrm{~mL}$ of solid or $10 \mathrm{~mL}$ of liquid medium; (ii) cultivation using an orbital shaker ( $80 \mathrm{rpm}$ ) in 0.1-litre Erlenmeyer flasks containing $20 \mathrm{~mL}$ of liquid medium; and (iii) cultivation in an airlift bioreactor (LKB-1607 fermentor Polyferm, Bromma, Sweden) in a 1-litre culture vessel filled with $0.5 \mathrm{~L}$ of liquid medium. In the bioreactor, the growth medium was aerated with sterile air. The air flow rate was $0.5 \mathrm{~L} / \mathrm{s}$. The cultures were incubated at $24{ }^{\circ} \mathrm{C}$ in the dark (root cultures) or 16-hour light/8-hour dark period and irradiation of $33 \mu \mathrm{mol} /\left(\mathrm{m}^{2} \cdot \mathrm{s}\right)$ (plantlets, calli and tumours).

\section{Determination of tissue growth and rosmarinic acid content}

Sustainability of the growth rate and RA production were analysed in 3 hormonally induced callus lines, 12 tumour lines, 7 lines of hormonally induced roots (normal roots) and 12 hairy root lines. For maintenance, tumours and hairy roots were subcultured on basal MS medium, calli on MS supplemented with $1 \mathrm{mg} / \mathrm{L}$ of 2,4-D and 0.1 $\mathrm{mg} / \mathrm{L}$ of kinetin, and normal roots on MS supplemented with $1 \mathrm{mg} / \mathrm{L}$ of NAA. Roots were subcultured on fresh medium every four weeks and calli and tumours every six weeks. To determine the fluctuation in growth and RA production, each of the 34 lines was analysed over a period of five years through 5 to 8 experiments (three to six independent replicates of the corresponding line per experiment). For experiments, lines were cultured (200 mg of initial inoculum) on the maintenance medium for 28 days, harvested and analysed. The impact of plant growth regulators on growth and RA production was examined in two experiments using selected lines, with six independent replicates per each line.

After harvesting, tissue mass was determined by weighing. Lyophilized tissue was homogenized with 70 $\%$ ethanol in an ultrasonic bath at $70{ }^{\circ} \mathrm{C}$ for $20 \mathrm{~min}$. The extracts were centrifuged at $10000 \times g$ for $1 \mathrm{~min}$ and the supernatants were filtered through a $0.45-\mu \mathrm{m}$ membrane filter. Samples were diluted and acidified with $50 \%$ methanol and $0.01 \% \mathrm{H}_{3} \mathrm{PO}_{4}$ in water. Extracted components were separated by high-performance liquid chromatography (HPLC) method on a PerkinElmer (Waltham, MA, USA) Series 200 chromatography system equipped with a vacuum degasser, quaternary pump, autosampler, diode array detector and Hypersil ODS column $(250 \mathrm{~mm} \times 4.6 \mathrm{~mm}$, particle size $5 \mu \mathrm{m})$. Separation of the sample compounds was isocratic with $50 \%$ methanol and $0.01 \% \mathrm{H}_{3} \mathrm{PO}_{4}$ in 
water. The injection volume was $0.02 \mathrm{~mL}$ and the flow rate $0.85 \mathrm{~mL} / \mathrm{min}$. Absorbance of the eluted compounds was measured at $330 \mathrm{~nm}$. The presence of RA in the extracts was confirmed by comparison of retention times and absorbance spectra with an authentic RA standard (Fluka, Buchs, Switzerland). Concentrations were determined based on the calibration curve (peak area vs. concentration) obtained for a wide concentration range.

\section{High-performance liquid chromatography analysis of phenolic compounds}

After four weeks hairy roots (cultured on MS medium and MS supplemented with $1 \mathrm{mg} / \mathrm{L}$ of NAA) and normal roots (cultured on MS supplemented with $1 \mathrm{mg} / \mathrm{L}$ of NAA) were harvested, rinsed with water and lyophilized. Lyophilized tissue was mixed with extraction solvent (80 $\%$ methanol and 1.2 $\mathrm{M}$ hydrochloride solution) in a mass per volume ratio of 1:80 g/mL. Samples were incubated for $30 \mathrm{~min}$ at $80^{\circ} \mathrm{C}$, with continuous shaking at $150 \mathrm{rpm}$ in a water bath. After incubation, the mixture was centrifuged for $15 \mathrm{~min}$ at $15000 \times \mathrm{g}$. The supernatant was removed and centrifuged again for $15 \mathrm{~min}$ at $15000 \times g$. A volume of $1 \mathrm{~mL}$ of supernatant was then retained for further analysis. Extracted components were separated by HPLC on an Agilent 1100 Series system (Agilent Technologies, Santa Clara, CA, USA) equipped with a quaternary pump, multiwave UV/VIS detector, autosampler, fraction collector and Zorbax RX-C18 column $(75 \mathrm{~mm} \times 4.6 \mathrm{~mm}$, particle size $3.5 \mu \mathrm{m}$, Agilent Technologies). The gradient used for the separation of compounds consisted of solvent $A$ (deionised water containing $0.05 \%$ trifluoroacetic acid), solvent B (20\% methanol containing $0.05 \%$ trifluoroacetic acid), solvent C (70 \% methanol containing $0.05 \%$ trifluoroacetic acid) and solvent D (100\% methanol). The solvent composition (A:B:C:D) changed as follows: 80:20:0:0 at $0 \mathrm{~min}, 0: 100: 0: 0$ at $4 \mathrm{~min}, 0: 0: 100: 0$ at $23 \mathrm{~min}, 0: 0: 0: 100$ at $27 \mathrm{~min}, 0: 0: 0: 100$ at $32 \mathrm{~min}$ and finally 80:20:0:0 at $33 \mathrm{~min}$. The injection volume was $0.02 \mathrm{~mL}$ and the flow rate 1.0 $\mathrm{mL} / \mathrm{min}$ at $35{ }^{\circ} \mathrm{C}$. Absorbance of the eluted compounds was measured at 268, 280,310, 350 and $374 \mathrm{~nm}$ and the obtained chromatograms were analysed using the ChemStation program (Agilent Technologies). Caffeic acid, ferulic acid, rosmarinic acid, cinnamic acid, quercetin, luteolin, kaempferol, isorhamnetin, and chrysin (all from Sigma-Aldrich, St. Louis, MO, USA) were used as standards. The presence of phenolics in the extracts was confirmed by comparison of retention times and absorbance spectra with those of the standards and by co-chromatography of extracts with the standard. Concentrations were determined based on the calibration curves (peak area $v s$. concentration) obtained for a wide concentration range.

\section{Light microscopy}

Images were acquired with an Axiovert $200 \mathrm{M}$ microscope operated by the AxioVision software v. 4.5 (Zeiss, Göttingen, Germany), using a 20×/0.5 Plan-Neofluar objective. Images were captured using an AxioCam camera (MrC, Zeiss). Processing and assembly were performed with Adobe Photoshop and Illustrator CS4 (Adobe Systems, San Jose, CA, USA).

\section{Statistical analysis}

The mean value and standard deviation (S.D.) for growth and RA production were calculated for each line in each experiment, and the mean value was calculated for each tissue type altogether. Student's $t$-test $(p \leq 0.05)$ was used for statistical analysis. Statistical significance of the differences between the investigated groups (C2, HR, NR7 and T3) was evaluated by the factorial ANOVA and their mean values were compared using Bonferroni correction. Differences were considered to be statistically significant at $\mathrm{p} \leq 0.05$

\section{Results and Discussion}

\section{Tissue growth and rosmarinic acid production}

The first report of C. blumei callus induction and its capacity to produce high amounts of RA was published by Razzaque and Ellis (23). Since then, in vitro cultures of different species, especially members of Lamiaceae, Boraginaceae and Apiaceae families were shown to accumulate RA or its derivatives $(24,25)$. Here we compared the growth and RA production of different tissues established from three C. blumei genotypes. All tested genotypes readily regenerated calli and roots. From the leaves cultured on solid MS medium supplemented with $1 \mathrm{mg} / \mathrm{L}$ of 2,4-D and $0.1 \mathrm{mg} / \mathrm{L}$ of kinetin calli were induced, while the MS supplemented with $1 \mathrm{mg} / \mathrm{L}$ of NAA stimulated adventitious roots. A. tumefaciens infection prompted tumours, while $A$. rhizogenes incited hairy root growth (Figs. $1 \mathrm{~b}$ and $\mathrm{c})$.

Regarding random transgene insertion in the plant genome, each tumour clump and each hairy root that grew vigorously on the medium without plant growth regulators was considered as a separate line. The structure and colour of tumour lines varied, while all hairy roots were morphologically similar (Figs. 1d and e). All tissue cultures were maintained on solidified ( $0.8 \%$ agar) medium, where they exhibited vigorous growth. In one subculture tissues stayed viable for up to eight weeks. Three callus lines, 7 lines of normal roots, 12 hairy root lines and 12 tumour lines were investigated.

In order to select the most reliable tissue for biotechnological RA production, we compared growth and RA production of different C. blumei tissues. In addition, three genotypes of in vitro cultured C. blumei plantlets were analyzed, shoot and roots separately (Figs. 1a and 2 ). Data were collected over a period of five years and each line was analysed in 5-8 experiments. Average fresh mass yield and RA production per tissue type were calculated (Figs. 2a and b). Over the examination time, fresh mass yield was fairly constant for all tissue types except tumour lines, which had considerable fluctuation in mass yield. Compared to other tested tissues, plantlet root and shoot growth were stable but weak. On average, callus yielded $1.2 \mathrm{~g}$ per dish, normal roots $1.8 \mathrm{~g}$ and hairy roots $3.1 \mathrm{~g}$ of fresh tissue mass in 28 days (Fig. 2b). Over the entire period of examination plantlet shoots and normal roots had consistent RA production, while in tumours, calli, plantlet roots and hairy roots RA production gradually declined over the first two years of cultivation (Fig. 2a). Average RA production by calli and tumours dropped 



Fig. 1. Coleus blumei plantlet (a) and tissues cultured in vitro. Two weeks after agrobacterial inoculation tumours (b) and hairy roots (c) developed on leaf explants cultured on MS medium without plant growth regulators. Six months after agrobacterial infection tumour lines (d) and hairy roots (e) were established. Bars are $10 \mathrm{~mm}$

from $3.4 \%$ in dry mass in the first cultivation year and remained stable at $1.5 \%$ in calli and $1.9 \%$ in tumours. Plantlet roots and hairy roots produced on average 4.9 and $4.1 \%$ RA in the first year, respectively, while RA production stabilized at $3.4 \%$ in plantlet roots and $3.3 \%$ in hairy roots. Shoots cultured in vitro accumulated $1.3 \%$ RA in the dry mass. The RA production of a particular callus or tumour line varied between individual subcultures. In contrast, during the 5-year examination period, individual normal and hairy root lines exhibited consistent RA accumulation (Fig. 2c). These results imply roots as a major source of RA, and confirm that RA plays an important physiological role in plant roots. In fact, RA has an inhibitory effect on soilborne microorganisms and represents a major compound produced in the root exudates upon microbial challenge (16). Still, normal roots induced by NAA application had significantly lower growth compared to hairy roots and were not a promising source for RA production. In comparison with hairy roots, normal
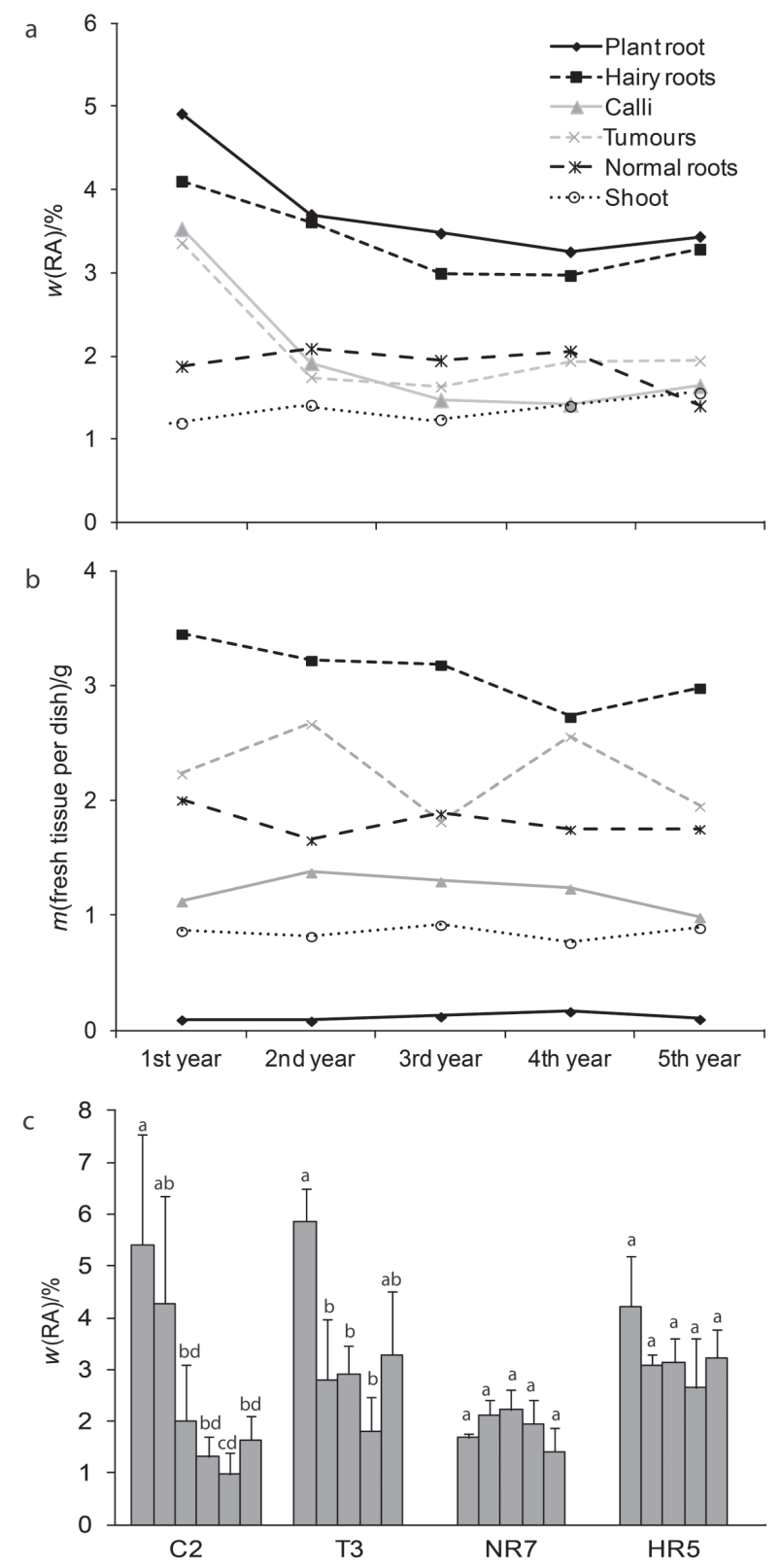

Fig. 2. Mean values of rosmarinic acid (RA) production in dry mass (a) and fresh mass yield of tissue (b) in callus, tumour, normal root and hairy root lines, as well as in plantlet shoots and roots of C. blumei over a 5-year period. The data were collected from at least five independent experiments for each line and the values from different lines of the same tissue type were pooled and averaged. Fluctuation of RA production (c) between subcultures of callus line 2 (C2), tumour line 3 (T3), normal root line 7 (NR7) and hairy root line 5 (HR5) over a period of five years. Each bar represents one subculture. Callus and normal root lines were cultured on MS medium with $1 \mathrm{mg} / \mathrm{L}$ of 2,4-dichlorophenoxyacetic acid (2,4-D) and $0.1 \mathrm{mg} / \mathrm{L}$ of kinetin, and $1 \mathrm{mg} / \mathrm{L}$ of 1 -naphthaleneacetic acid (NAA), respectively. Tumour, hairy root lines and plantlets were cultured on MS medium. Tissue was harvested after 28 days of cultivation on the above specified medium and plantlets were harvested after a 3 -month cultivation period. Values represent the mean of 3-6 measurements \pm standard deviation (S.D.). Statistical significance of the differences between the investigated groups was evaluated by the factorial ANOVA and their mean values were compared using Bonferroni correction. Differences were considered to be statistically significant at $p \leq 0.05$. Mean values denoted by the same letter did not differ significantly 
roots had up to four times smaller diameter (Fig. 3a) and yielded only half the fresh mass per dish and produced three times lower amounts of RA.

Taking specific types of tissue into consideration, the highest heterogeneity in growth and RA content were noted among tumour lines. Some tumour lines were exceptionally productive upon establishment, but over a longer cultivation period their productivity decreased. In addition, over a period of five years, tumours changed morphologically and some lines strongly and irreversibly decreased their growth rate, yet still accumulated RA.

Hairy root lines had the highest mean growth over the 5-year period showing consistent growth and RA production. Hairy root line 8 (HR8) produced the highest mean RA level (5.81 \%) and grew vigorously with $3.87 \mathrm{~g}$ of fresh tissue mass per dish when cultured statically in $10 \mathrm{~mL}$ of liquid medium. The RA yield measured for line HR8 was $452.2 \mathrm{mg} / \mathrm{L}$. Hairy roots induced with A. rhizogenes have become popular over the last couple of decades. Their cultures have many advantages, including biochemical and genetic stability, independence from seasonal and geographical conditions, fast hormone-independent growth, and the ability to produce secondary metabolites at the levels comparable to those of naturally grown plants (26). The majority of root cells are differentiated and many secondary metabolites are synthesized simultaneously with root growth (27). Hairy roots of different species have been tested for RA production (28-30). In most cases they synthesize higher amounts of RA compared to intact plants, and different elicitors not only induce RA production, but stimulate its excretion into the culture medium (31-33).

\section{The effect of plant growth regulators on growth and rosmarinic acid production}

Tumour tissue formed bulky clusters (Fig. 3b) unsuitable for cultivation in large volumes since in liquid media the clumps were submerged and tissue growth was attenuated. Unlike the tumour tissue, hairy roots grew vigorously in liquid medium with shaking (Fig. 3c). In order to enable good tumour tissue growth 2,4-D, a well-known synthetic auxin used for establishment of many cell suspension cultures, was added to the medium. Different 2,4-D concentrations were tested. For the majority of tumour lines, the addition of 2,4-D to the culture medium did not induce satisfactory loosening of tissue and had a significantly negative effect on growth and RA production. We successfully established a tumour cell suspension by adding $1 \mathrm{mg} / \mathrm{L}$ of 2,4-D to the cultivation medium for the friable tumour line (T1), but 2,4-D diminished the growth of T1 tumour by $60 \%$ and RA production by $35 \%$ (Fig. 3d). The hard and compact tumours proved to be inconvenient for cultivation as suspensions even with higher 2,4-D concentrations (up to $5 \mathrm{mg} / \mathrm{L}$ ). Due to the inability to establish fine suspensions and along with unstable growth and RA production, we concluded that tumours established in our laboratory were not satisfactory for upscaling and mass production. Campanoni and Nick (34) showed that 2,4-D efficiently triggers cell division but not cell expansion. Small, actively dividing cells lack vacuoles, and since RA accumulates there (15), this may be the reason for the negative effect that 2,4-D had on mass yield and RA production. Similar negative effects of 2,4-D are observed on the production of different secondary metabolites (35) as well as on RA production and growth of Ocimum sanctum callus cultures (36).

Although hairy root cultures established in our laboratory were independent of plant growth regulators (Fig. $3 c)$, NAA strongly stimulated hairy root growth when added to the culture medium. NAA enhanced the growth by $251 \%$ while RA production stayed constant (Fig. 3e). This finally resulted in 2.5 times higher RA yield in hairy roots cultured on medium supplemented with NAA. Positive effects of auxins on hairy root growth and RA production have been described for Nepeta cataria (37). NAA is shown to stimulate cell elongation and vacuole expansion (34). Untransformed normal roots cultured on media supplemented with NAA had a significantly lower growth rate and changed root morphology (Fig. 3a). Despite the strong impact of NAA on the growth, there was little influence on the spectrum of root phenolics. All compounds that were present in hairy roots cultured on medium with NAA were also present in untreated hairy roots (Fig. 3f). Differences in phenolic contents between normal root and hairy root cultures were mostly quantitative. Thus, hairy roots produced a significantly higher content of RA, as well as several other unidentified components. However, several components with a retention time between 19 and 27 min were detected in untreated hairy roots but were not present in normal or hairy roots cultured on the medium with NAA. Normal and hairy roots differed in one component, with a peak at $18.8 \mathrm{~min}$, which was not synthesized by hairy roots. The addition of NAA was not accompanied by significant increase in RA and other phenolics compared to untreated hairy roots, except for the compound eluting at $6.5 \mathrm{~min}$. Still, untreated hairy roots had several components not detected in hairy roots cultured on the medium with NAA (Fig. 3f) indicating a distinct effect of NAA on the phenylpropanoid biosynthetic pathway.

ABA is an essential signal for plant resistance to pathogens and biosynthesis of secondary metabolites (38). Previous studies have shown that exogenous ABA application affects growth and secondary metabolism, but the effects of ABA on RA synthesis in C. blumei have not been examined so far. ABA affects the phenylpropanoid pathway and improves the colour of grape berries (39), induces production of phenolic acids in Salvia miltiorrhiza hairy roots (40), while treatment with moderate concentrations of ABA does not affect hairy root growth (41). In C. blumei hairy roots, the addition of $1 \mathrm{mg} / \mathrm{L}$ of ABA to the cultivation medium enhanced RA production by $164 \%$ while it did not affect growth. At the same time ABA slightly reduced tumour RA production (Figs. 3d and e), so further examination of these distinct ABA effects on different tissue types is required.

In our previous investigation we have shown the stimulating effect of methyl jasmonate and yeast extract on RA production in hairy roots (22). Here, the application of ABA strongly enhanced RA production and did not affect growth, which makes ABA one of the strongest inducers, as well as the most promising agent for elicitation of RA synthesis in C. blumei hairy roots. 



$m$ (fresh tissue per dish)/g

$w(\mathrm{RA}) / \%$


Fig. 3. Normal roots induced with 1-naphthaleneacetic acid (NAA) (a, upper image) were thinner, with smaller root meristem than hairy roots induced with Agrobacterium rhizogenes (a, image below). Bar is $1 \mathrm{~mm}$. Large tumour clusters (b) and hairy root culture (c) in liquid MS medium on an orbital shaker. Addition of $1 \mathrm{mg} / \mathrm{L}$ of 2,4-dichlorophenoxyacetic acid (2,4-D) or abscisic acid (ABA) to the liquid MS medium attenuated growth and rosmarinic acid (RA) production in tumour line T1 (d), while growth and RA production of hairy root line HR1 were induced with $1 \mathrm{mg} / \mathrm{L}$ of NAA and $1 \mathrm{mg} / \mathrm{L}$ of ABA, respectively (e). Values are the mean of 6 measurements \pm S.D. Differences in fresh mass and RA content were tested using $t$-test. Significant differences $(\mathrm{p} \leq 0.05)$ compared to the control (MS) are indicated by asterisk. HPLC chromatograms (f) of the extracts from normal roots after acid hydrolysis (NR NAA) compared to the hydrolysed extracts from hairy roots (HR 0) and hairy roots cultured on MS with 1 $\mathrm{mg} / \mathrm{L}$ of NAA (HR NAA). The chromatograms were obtained using a gradient elution system (see Materials and Methods) and detection was carried out at $280 \mathrm{~nm}$. Black arrows indicate phenolic compounds which were produced in significantly higher amounts in hairy roots compared to normal roots

\section{The effect of the cultivation method on growth and rosmarinic acid production}

Since nutrients are uniformly available in liquid medium, we expected better tissue growth under shaking conditions but the same tissue line cultured on solid or in liquid medium showed no significant differences in growth rate and RA production (Fig. 4). Although not significantly, RA production of tumour lines was slightly elevated on solid medium. Hairy roots grew vigorously in liquid medium with shaking (Figs. 3c and e), as well as in liquid static cultures in $\varnothing 90-\mathrm{mm}$ Petri dishes. Reliable RA production and good growth rate encouraged us to cultivate hairy roots in an airlift bioreactor (Fig. 5). Thus, $15 \mathrm{~g}$ of hairy roots were inoculated in $0.5 \mathrm{~L}$ of MS medium supplemented with $1 \mathrm{mg} / \mathrm{L}$ of NAA. After four weeks, (238.4 \pm 52.1) $\mathrm{g}$ of root tissue were harvested. Hairy roots grown in a bioreactor produced $(3.5 \pm 0.8) \% \mathrm{RA}$ in dry mass, which on average meant $871.8 \mathrm{mg}$ of RA per litre. Thus, the RA content in hairy roots in bioreactor was two times higher compared to that in flasks/Petri dishes. Rosmarinic acid production in laboratory bioreactors was investigated in cell cultures of $C$. blumei $(42,43)$ and other species (44-46) while, to our knowledge, this is the first report where a hairy root culture in a bioreactor has been ex-

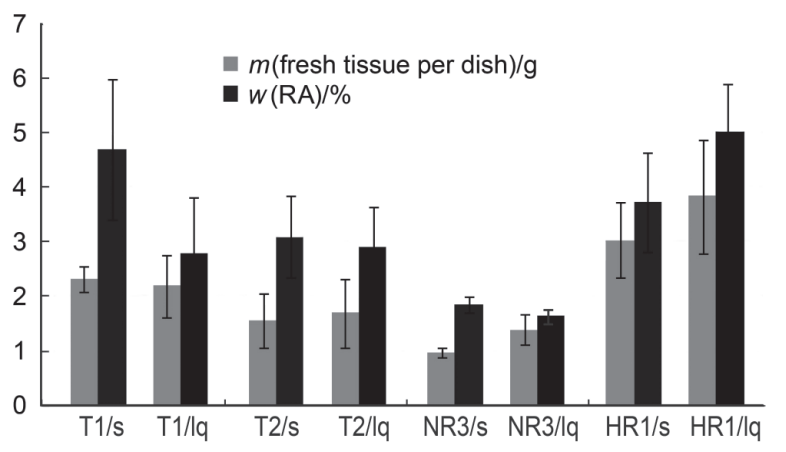

Fig. 4. Fresh mass of tissue and rosmarinic acid (RA) content in tumours induced with Agrobacterium tumefaciens strain A281 (T1) and A. tumefaciens strain B6S3 (T2), hairy roots (HR1) induced with Agrobacterium rhizogenes A4 and normal roots (NR3). Tissues were cultured on solid (s) or in liquid (lq) medium on an orbital shaker $(80 \mathrm{rpm})$. Values represent the mean of 8 measurements ( 2 independent experiments) \pm S.D. Cultivation on solid or in liquid medium did not induce significant differences in growth or RA production in the investigated tissues ( $t$ -test, $\mathrm{p} \leq 0.05$ )
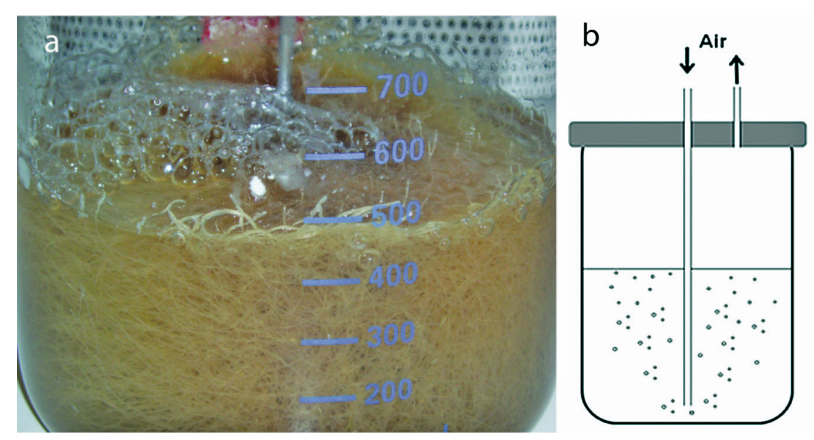

Fig. 5. Mass proliferation of hairy roots cultured in an airlift bioreactor (a) and schematic representation of the airlift bioreactor (b) 
ploited for RA production. Vigorous hairy root growth and reproducible and stable rates of RA production in an airlift bioreactor indicated suitability for upscaling, thus meeting the first requirement for large-scale biotechnological production. Therefore, we propose that C. blumei hairy roots could be suitable for mass production in industrial scale bioreactors.

\section{Conclusion}

In vitro cultured callus, tumours, normal and hairy roots of $C$. blumei had the ability to accumulate significantly higher levels of RA than original plants. Over a long period, root cultures showed a constant and reliable growth and RA production, whereas growth and RA production in the callus and tumours varied significantly between subcultures. Hairy roots grew vigorously and produced high RA amounts when cultured on solid or in liquid media as well as in an airlift bioreactor. Addition of NAA enhanced growth while ABA significantly improved the RA production in hairy roots.

\section{Acknowledgements}

This work was supported by Croatian Ministry of Science, Education and Sports, grant 119-1191196-1225. We are grateful to Lucija Neal for proofreading the manuscript.

\section{References}

1. Rodríguez-Sahagún A, Gutierrez-Lomelí M, CastellanosHernández O. Plant cell and tissue culture as a source of secondary metabolites. In: Orhan IE, editor. Biotechnological production of plant secondary metabolites. Sharjah, United Arab Emirates: Bentham Science Publishers; 2012. pp. 3-20.

2. Ruffoni B, Pistelli L, Bertoli A, Pistelli L. Plant cell cultures: bioreactors for industrial production. In: M.T. Giardi, G. Rea, B. Berra, editors. Bio farms for nutraceuticals: functional food and safety control by biosensors. New York, NY, USA: Landes Bioscience and Springer Science+Business Media; 2010. pp. 203-21.

3. Andrade-Cetto A. Ethnobotanical study of the medicinal plants from Tlanchinol, Hidalgo, Mexico. J Ethnopharmacol. 2009;122:163-71.

http://dx.doi.org/10.1016/j.jep.2008.12.008

4. Ong HC, Norzalina J. Malay herbal medicine in Gemencheh, Negri Sembilan, Malaysia. Fitoterapia. 1999;70:10-4. http://dx.doi.org/10.1016/S0367-326X(98)00023-9

5. Rasineni GK, Reddy AR. Free radical quenching activity and polyphenols in three species of Coleus. J Med Plants Res. 2008;2:285-91.

6. Fraga CG, editor. Plant Phenolics and Human Health - Biochemistry, Nutrition, and Pharmacology. Hoboken, NJ, USA: John Wiley \& Sons, Inc.; 2010.

7. Reichling J, Nolkemper S, Stintzing FC, Schnitzler P. Impact of ethanolic Lamiaceae extracts on Herpesvirus infectivity in cell culture. Forsch Komplement Med. 2008;15:313-20. http://dx.doi.org/10.1159/000164690

8. Bulgakov VP, Inyushkina YV, Fedoreyev SA. Rosmarinic acid and its derivatives: biotechnology and applications. Crit Rev Biotechnol. 2012;32:203-17. http://dx.doi.org/10.3109/07388551.2011.596804

9. Zdařilová A, Svobodová A, Šimánek V, Ulrichová J. Prunella vulgaris extract and rosmarinic acid suppress lipopolysac- charide-induced alteration in human gingival fibroblasts. Toxicol in Vitro. 2009;23:386-92. http://dx.doi.org/10.1016/j.tiv.2008.12.021

10. Ono K, Li L, Takamura Y, Yoshiike $\mathrm{Y}$, Zhu L, Han F, et al. Phenolic compounds prevent amyloid $\beta$-protein oligomerization and synaptic dysfunction by site-specific binding. J Biol Chem. 2012;287:14631-43. http://dx.doi.org/10.1074/jbc.M111.325456

11. Petersen M, Abdullah Y, Benner J, Eberle D, Gehlen K, Hucherig $\mathrm{S}$, et al. Evolution of rosmarinic acid biosynthesis. Phytochemistry. 2009;70:1663-79. http://dx.doi.org/10.1016/j.phytochem.2009.05.010

12. Bauer N, Leljak-Levanić D, Jelaska S. Rosmarinic acid synthesis in transformed callus culture of Coleus blumei Benth. Z Naturforsch C. 2004;59:554-60.

13. Xiao Y, Zhang L, Gao S, Saechao S, Di P, Chen J, et al. The $\mathrm{c} 4 \mathrm{~h}$, tat, hppr and hppd genes prompted engineering of rosmarinic acid biosynthetic pathway in Salvia miltiorrhiza hairy root cultures. PLoS ONE. 2011;6:e29713. http://dx.doi.org/10.1371/journal.pone.0029713

14. Petersen M. Biosynthesis and accumulation of rosmarinic acid in plant cell cultures. In: Fu TJ, Singh G, Curtis W, editors. Plant cell and tissue culture for the production of food ingredients. New York, NY, USA: Springer; 1999. pp. 61-73.

15. Häusler E, Petersen $M$, Alfermann A. Isolation of protoplasts and vacuoles from cell suspension cultures of Coleus blumei Benth. Plant Cell Rep. 1993;12:510-2. http://dx.doi.org/10.1007/BF00236097

16. Bais HP, Walker TS, Schweizer HP, Vivanco JM, Root specific elicitation and antimicrobial activity of rosmarinic acid in hairy root cultures of Ocimum basilicum. Plant Physiol Biochem. 2002;40:983-95. http://dx.doi.org/10.1016/S0981-9428(02)01460-2

17. Park SU, Uddin R, Xu H, Kim YK, Lee SY. Biotechnological applications for rosmarinic acid production in plant. Afr J Biotechnol. 2008;7:4959-65.

18. Zagrajski N, Leljak-Levanić D, Jelaska S. Organogenesis and callogenesis in nodal, internodal and leaf explants of Coleus blumei Benth. Period Biol. 1997;99:67-76.

19. Murashige T, Skoog F. A revised medium for rapid growth and bio assays with tobacco tissue cultures. Physiol Plantarum. 1962;15:473-97. http://dx.doi.org/10.1111/j.1399-3054.1962.tb08052.x

20. Bauer N, Bogdan M, Jelaska S. Morphogenesis and influence of selective and antimicrobial substances on root development in Coleus blumei Benth. Propag Ornam Plants. 2008;8: 65-71.

21. Bauer N, Leljak-Levanić D, Mihaljević S, Jelaska S. Genetic transformation of Coleus blumei Benth. using Agrobacterium. Food Technol Biotechnol. 2002;40:163-9.

22. Bauer N, Kiseljak D, Jelaska S. The effect of yeast extract and methyl jasmonate on rosmarinic acid accumulation in Coleus blumei hairy roots. Biol Plant. 2009;53:650-6. http://dx.doi.org/10.1007/s10535-009-0118-8

23. Razzaque A, Ellis BE. Rosmarinic acid production in Coleus cell cultures. Planta. 1977;137:287-91. http://dx.doi.org/10.1007/BF00388164

24. Shekarchi M, Hajimehdipoor H, Saeidnia S, Gohari AR, Hamedani MP. Comparative study of rosmarinic acid content in some plants of Labiatae family. Pharmacogn Mag. 2012;8:37-41. http://dx.doi.org/10.4103/0973-1296.93316

25. Petersen M. Rosmarinic acid: new aspects. Phytochem Rev. 2013;12:207-27.

http://dx.doi.org/10.1007/s11101-013-9282-8 
26. Zhou ML, Zhu XM, Shao JR, Tang YX, Wu YM. Production and metabolic engineering of bioactive substances in plant hairy root culture. Appl Microbiol Biotechnol. 2011;90: 122939.

http://dx.doi.org/10.1007/s00253-011-3228-0

27. Srivastava S, Srivastava AK. Hairy root culture for mass-production of high-value secondary metabolites. Crit Rev Biotechnol. 2007;27:29-43. http://dx.doi.org/10.1080/07388550601173918

28. Li W, Koike K, Asada Y, Yoshikawa T, Nikaido T. Rosmarinic acid production by Coleus forskohlii hairy root cultures. Plant Cell Tiss Organ Cult. 2005;80:151-5. http://dx.doi.org/10.1007/s11240-004-9541-x

29. Lee $\mathrm{S}, \mathrm{Xu} \mathrm{H}, \mathrm{Kim} \mathrm{Y}$, Park S, Rosmarinic acid production in hairy root cultures of Agastache rugosa Kuntze. World J Microbiol Biotechnol. 2008;24:969-72. http://dx.doi.org/10.1007/s11274-007-9560-y

30. Weremczuk-Jeżyna I, Grzegorczyk-Karolak I, Frydrych B, Królicka A, Wysokińska H, Hairy roots of Dracocephalum moldavica: rosmarinic acid content and antioxidant potential. Acta Physiol Plant. 2013;35:2095-103. http://dx.doi.org/10.1007/s11738-013-1244-7

31. Georgiev M, Kuzeva S, Pavlov A, Kovacheva E, Ilieva M. Enhanced rosmarinic acid production by Lavandula vera MM cell suspension culture through elicitation with vanadyl sulfate. Z Naturforsch C. 2006;61:241-4.

32. Georgiev M, Kuzeva S, Pavlov A, Kovacheva E, Ilieva M. Elicitation of rosmarinic acid by Lavandula vera MM cell suspension culture with abiotic elicitors. World J Microbiol Biotechnol. 2007;23:301-4. http://dx.doi.org/10.1007/s11274-006-9214-5

33. Vuković R, Bauer N, Ćurković-Perica M. Genetic elicitation by inducible expression of $\beta$-cryptogein stimulates secretion of phenolics from Coleus blumei hairy roots. Plant Sci. 2013;199-200:18-28.

http://dx.doi.org/10.1016/j.plantsci.2012.10.009

34. Campanoni P, Nick P. Auxin-dependent cell division and cell elongation. 1-Naphthaleneacetic acid and 2,4-dichlorophenoxyacetic acid activate different pathways. Plant Physiol. 2005;137:939-48. http://dx.doi.org/10.1104/pp.104.053843

35. Rao SR, Ravishankar GA. Plant cell cultures: Chemical factories of secondary metabolites. Biotechnol Adv. 2002;20:101-53. http://dx.doi.org/10.1016/S0734-9750(02)00007-1

36. Hakkim FL, Kalyani S, Essa M, Girija S, Song H. Production of rosmarinic acid in Ocimum sanctum (L.) cell suspension cultures by the influence of growth regulators. Int J Biol Med Res. 2011;2:1158-61.

37. Yang YK, Lee SY, Park WT, Park NI, Park SU. Exogenous auxins and polyamines enhance growth and rosmarinic acid production in hairy root cultures of Nepeta cataria L. Plant Omics J. 2010;3:190-3.

38. Adie BAT, Pérez-Pérez J, Pérez-Pérez MM, Godoy M, Sánchez-Serrano JJ, Schmelz EA, et al. ABA is an essential signal for plant resistance to pathogens affecting JA biosynthesis and the activation of defenses in Arabidopsis. Plant Cell. 2007;19:1665-81.

http://dx.doi.org/10.1105/tpc.106.048041

39. Peppi MC, Walker MA, Fidelibus MW. Application of abscisic acid rapidly upregulated UFGT gene expression and improved color of grape berries. Vitis. 2008;47:11-4.

40. Liang Z, Ma Y, Xu T, Cui B, Liu Y, Guo Z, et al. Effects of abscisic acid, gibberellin, ethylene and their interactions on production of phenolic acids in Salvia miltiorrhiza Bunge hairy roots. PLoS ONE. 2013;8:e72806. http://dx.doi.org/10.1371/journal.pone.0072806

41. Hao G, Ji H, Li Y, Shi R, Wang J, Feng L, et al. Exogenous ABA and polyamines enhanced salvianolic acids contents in hairy root cultures of Salvia miltiorrhiza Bge. f. alba. Plant Omics J. 2012;5:446-52.

42. Ulbrich B, Wiesner W, Arens H. Large-scale production of rosmarinic acid from plant cell cultures of Coleus blumei Benth. In: Neumann KH, Barz W, Reinhard E, editors. Primary and secondary metabolism of plant cell cultures. Berlin, Germany: Springer-Verlag; 1985. pp. 293-303.

43. Martinez B, Park CH. Immobilization of Coleus blumei cells in a column reactor using a spray feeding system. Biotechnol Tech. 1994;8:301-6. http://dx.doi.org/10.1007/BF02428971

44. Su W, Humphrey A. Production of rosmarinic acid from perfusion culture of Anchusa officinalis in a membrane-aerated bioreactor. Biotechnol Lett. 1991;13:889-92. http://dx.doi.org/10.1007/BF01022093

45. Su WW, Lei F, Kao NP. High density cultivation of Anchusa officinalis in a stirred-tank bioreactor with in situ filtration. Appl Microbiol Biotechnol. 1995;44:293-9. http://dx.doi.org/10.1007/BF00169919

46. Pavlov A, Georgiev M, Ilieva M, Production of rosmarinic acid by Lavandula vera MM cell suspension in bioreactor: effect of dissolved oxygen concentration and agitation. World J Microbiol Biotechnol. 2005;21:389-92. http://dx.doi.org/10.1007/s11274-004-3982-6 